\title{
A PESQUISA EM DESIGN DE MODA NO BRASIL A PARTIR DE PERIÓDICOS DA ÁREA: TECNOLOGIA PARA ANÁLISE SISTEMÁTICA
}

HORN, Bibiana Silveira; Me.; Centro Universitário Ritter dos Reis bibiana.silveira.horn@gmail.com

RIBEIRO, Vinicius Gadis; Dr.; Centro Universitário Ritter dos Reis vinicius@uniritter.edu.br

GAVIÃO, Wilson; Dr.; Centro Universitário Ritter dos Reis wgaviao@gmail.com

Resumo: Este artigo apresenta um estudo realizado a partir de periódicos qualificados da área de Design de Moda. O objetivo deste trabalho é apresentar o panorama geral das pesquisas acadêmicas nessa área, assumindo-se que na publicação em periódicos ocorre a divulgação de resultados de projetos de pesquisa. O trabalho analisa 224 artigos publicados em três diferentes periódicos. A metodologia empregada foi a análise sistemática, tendo sido aplicadas algumas das técnicas de mineração de dados. Ao final, verifica-se que a técnica de mineração de dados, combinada com estatística descritiva apoiaram a análise sistemática, proporcionou a obtenção dos resultados deste panorama, bem como o perfil de cada periódico analisado.

Palavras-chave: Epistemologia do Design, Análise Sistemática, Mineração de Dados, Artigos, Periódicos Nacionais.

\section{INTRODUÇÃO}

Com base Caldas (2006) e Pires (2002), é possível afirmar que a produção científica em design de moda no Brasil, enquanto área de pesquisa e disseminação de conhecimento, é recente. A maioria dos cursos de nível superior são relativamente novos - porém houve uma rápida difusão de cursos de design de moda no país. Isso se deve a vários fatores (demanda de empresas por profissionais capacitados, altos valores econômicos gerados pelo mercado de moda, relação empresa e universidade, são alguns exemplos), e, conseqüentemente desencadeia a necessidade de profissionais docentes para atuarem nestes cursos.

No Brasil, o desenvolvimento do Design de Moda como campo de pesquisa científica deve-se em grande parte a trabalhos de dissertações e teses, eventos e um número ainda significativamente pequeno de periódicos. O presente trabalho é resultado da investigação conduzida para a dissertação de mestrado intitulada "Uma análise da pesquisa em design de moda no Brasil a partir de periódicos da área". Seu 
problema central foi descrever o panorama geral acadêmico da Moda no Brasil - em especial, do ponto de vista dos métodos de pesquisa -, a partir de periódicos brasileiros da área de moda.

O objetivo principal deste trabalho foi obter o panorama geral das pesquisas acadêmicas em design de moda em periódicos brasileiros da área desde 2007 até junho de 2013. Entende-se aqui que os resultados de tais processos investigatórios se fazem presentes em periódicos. Os objetivos secundários consistem em: (i) identificar a produção acadêmica de moda, mais especificamente no Brasil; (ii) verificar tendências para pesquisa, no que diz respeito a temática, identificando os temas mais explorados nos periódicos; (iii) investigar quais são as instituições de maior produção de conhecimento, apontando suas regiões; (ix) identificar a aplicação de metodologias de pesquisa em cada um dos periódicos

O foco do estudo concentrou-se na análise de três periódicos acadêmicos de moda, revista Dobras ${ }^{1}$, IARA ${ }^{2}$ e Modapalavra ${ }^{3}$. Trata-se de uma pesquisa quantitativa, a partir da categorização de dados obtidos a partir dos artigos publicados nesses veículos. Quanto aos objetivos, a pesquisa é descritiva, pois busca familiarizar-se com o assunto, investiga e descreve fenômenos submetidos a análises. A técnica utilizada foi mineração de dados.

A decisão por analisar periódicos deve-se ao acesso às informações, e visto que já há uma pesquisa que analisou artigos publicados em eventos de design (Andrade Neto, 2012) e uma pesquisa que verificou teses e dissertações de moda (Bonadio, 2010). Ainda não foram feitas análises em periódicos acadêmicos nacionais específicos de moda.

Este artigo está estruturado da seguinte forma: na seção dois são apresentadas algumas significações de moda propostas por diferentes autores, e a definição de moda que foi utilizada como referência neste trabalho. A metodologia de pesquisa apresentada na seção três -, é dividida em quatro partes: recorte da pesquisa, préprocessamento, mineração de dados e pós-processamento. A seção quatro apresenta a análise dos resultados e a seção cinco apresenta a conclusão do trabalho.

\section{DESIGN DE MODA}

Há varias percepções e pontos de vista sobre a moda ${ }^{4}$. Pode-se contextualizar, por exemplo, a moda a partir de fatores mercadológicos, sociológicos e culturais, como verifica-se na figura 1 . A moda passou de algo visto como superficial, para algo que causa impacto e interfere na sociedade de várias maneiras.

\footnotetext{
${ }^{1}$ http://www.estacaoletras.com.br/revista_dobras.php

${ }^{2}$ http://www.iararevista.sp.senac.br/

${ }^{3}$ http://www.ceart.udesc.br/modapalavra/edicao11/

4 Para este trabalho, foi realizada uma pesquisa mais extensa sobre: Surgimento dos estudos acadêmicos e escolas de moda no Brasil, Relação entre moda e design, Design de moda na pósgraduação e Pesquisa de moda no meio acadêmico e disseminação de conhecimento. Disponível em: HORN, B. S. Uma análise da pesquisa em design de moda no Brasil a partir de periódicos da área. 2014. Dissertação (Mestrado) Centro Universitário Ritter dos Reis, Curso de Pós-Graduação em Design.
} 


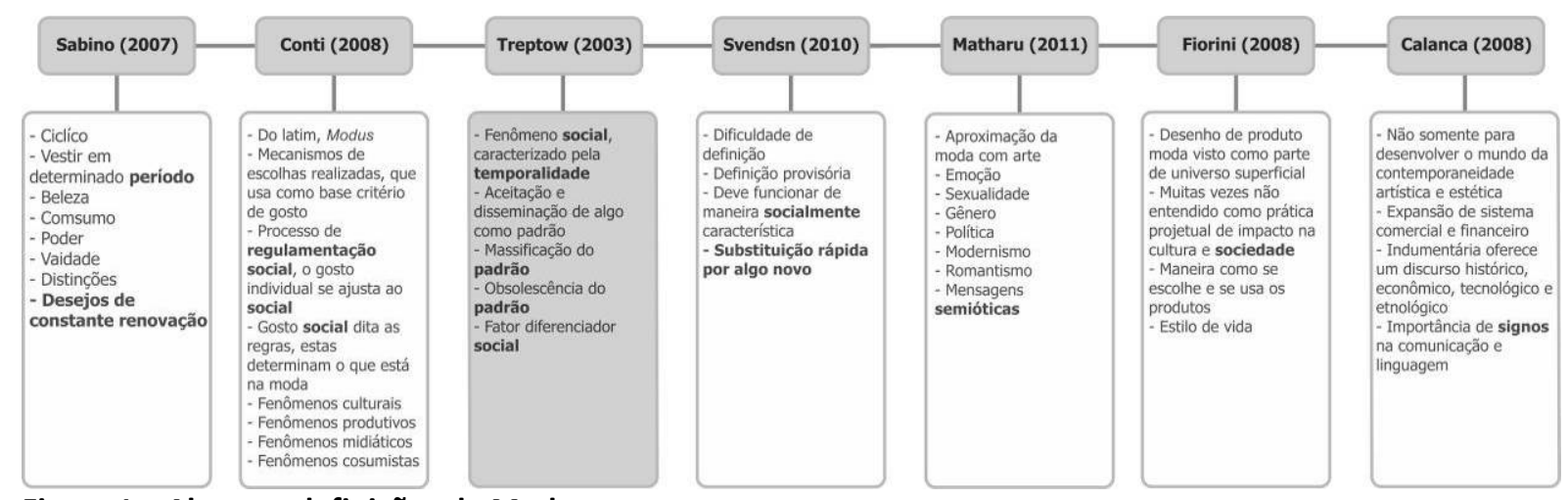

Figura 1 - Algumas definições de Moda

Fonte: Elaborado pelo autor, com base na pesquisa realizada.

Lipovetsky (2009) relaciona a moda com as "teorias de distinção", e para ele a moda é muito mais do que um fator diferenciador de classes. A moda para ele é "em primeiro lugar um dispositivo social caracterizado por sua temporalidade particularmente breve." (LIPOVETSKY, 2009, p.25). O autor percebe a moda como o culto ao novo, diretamente relacionada à individualidade, algo que trouxe à sociedade a valorização das escolhas individuais, libertando as pessoas de antigos costumes.

Considerando o autor, é possível afirmar que a moda também está inserida em setores como mobiliário, objetos e linguagens, porém o vestuário é a maior referência para a problemática da moda. Durante muito tempo o domínio da aparência teve o seu lugar de destaque na história da moda. "Mas até os séculos XIX e XX foi o vestuário, sem dúvida alguma, que encarnou mais ostensivamente o processo de moda." (LIPOVETSKY, 2009, p.25)

Com base nos autores estudados, este trabalho terá o referencial de moda como fenômeno social relacionado à temporalidade, que em determinada época da história pode ter sido percebido como diferenciador de classes, mas que antes de qualquer coisa é um fator de individualidade diretamente relacionado ás aparências e também ligado a questões culturais, sociais, políticas, antropológicas e econômicas.

A próxima seção apresenta a metodologia do presente estudo.

\section{METODOLOGIA}

O presente trabalho conduziu uma pesquisa quantitativa, de caráter descritivo. Com base em Collado, Lucio e Sampieri (1997), pode-se afirmar que a pesquisa descritiva tem o propósito de investigar e descrever situações, como são e como se manifestam determinados fenômenos, os quais são submetidos à análise.

O método de pesquisa é análise sistemática, tendo como diferencial o emprego de algumas técnicas de mineração de dados com auxílio de software. No entanto, primeiramente os dados passaram por um processo de categorização. $O$ foco da pesquisa foi direcionado para publicações acadêmicas na área de design de moda e esta foi realizada a partir dos seguintes recortes: local, tipo de publicação e periódicos selecionados. Foram analisados artigos publicados em três periódicos acadêmicos brasileiros de moda.

\subsection{Recorte de pesquisa}

Definiram-se publicações brasileiras, visto que a moda como área acadêmica no Brasil, é relativamente nova, e desta forma poderá se contribuir com o fortalecimento 
da área. Obtendo o panorama geral das pesquisas acadêmicas em design de moda em periódicos brasileiros da área desde 2007 até junho de 2013, que é o objetivo da pesquisa. O objeto de pesquisa foi definido como artigos de periódicos acadêmicos não sendo incluídos artigos de congressos e eventos.

Para escolha dos periódicos, buscou-se indicação através da ANPEDesign (Associação Nacional de pesquisa em Design) e da ABEPEM (Associação Brasileira de Estudos e Pesquisas em Moda), de quais são os periódicos considerados relevantes na área de moda. A ANPEDesign (Associação Nacional de pesquisa em Design), através de contato via e-mail, indicou os anais de congresso do P\&D e CIPED como fonte de pesquisa; porém, o foco de pesquisa são periódicos especificamente de moda. Quando questionada, a associação afirmou não possuir nenhum projeto voltado para o segmento de moda. Com isso, definiu-se mais um recorte: periódicos, cadastrado no portal CAPES na área 29 - que compreeende as áreas de Arquitetura, Urbanismo e Design. Dessa forma, aumentou-se o nível do grau de exigência dos artigos. Não foram selecionados por estrato, já que há poucas revistas específicas na área de design de moda.

Em contato com a ABEPEM (Associação Brasileira de Estudos e Pesquisas em Moda) foram indicadas duas revistas: Dobras da editora Estação das Letras e Cores; e IARA: Revista de moda, arte e cultura, do SENAC ${ }^{5}$. Conforme verificação feita em julho de 2013, estes dois periódicos possuem cadastro na área de arquitetura e urbanismo, assim como outro periódico eletrônico também encontrado, Modapalavra, que pertence a UDESC.

Apesar de estes periódicos apresentarem outros conteúdos além dos artigos científicos, o presente trabalho levou em consideração somente o que estiver classificado como artigo pelos próprios periódicos, e foram consideradas as publicações até junho de 2013.

\subsection{Pré-processamento}

Esta etapa iniciou com a coleta de dados. Foram totalizados duzentos e setenta e seis artigos, todos foram lidos e tiveram seus dados coletados, porém alguns não tinham uma relação direta com a moda, eram de áreas correlatas e foi necessária a criação de categorias para fazer essa separação. E posteriormente realizar uma análise mais profunda somente dos artigos de moda como foi a proposta inicial do trabalho.

Desenvolveu-se uma tabela para coleta de dados, onde primeiramente foram inseridos os seguintes dados dos artigos, sendo eles independente de artigos específicos de moda ou não: periódico, volume, mês e ano de publicação, instituição de ensino, título, tema (um resumo, apenas para registro do que tratava cada pesquisa), palavras chave e se o artigo pertencia a da área da moda ou era de uma área correlata. Desta forma todos os artigos entram para contagem e verificação geral.

Com base na interpretação das leituras dos artigos e na definição de moda apresentada na seção dois, foram criadas as seguintes categorias temáticas: História da Moda , História da Moda no Brasil, Moda e Comportamento, Moda e Sociedade, Filosofia da Moda, Moda e Arte, Moda e Cultura, Moda e Literatura, Moda e Artesanato, Semiótica na Moda, Relação corpo e moda, Consumo de moda, Moda e

\footnotetext{
${ }^{5}$ Estas informações foram enviadas por Kathia Castilho, atual presidente da associação e pesquisadora na área de moda já há bastante tempo.
} 
Comunicação, Marketing de Moda, Mercado de Moda, Indústria da Moda, Ensino de Moda, Projeto de Moda, Terminologias de Moda, Ergonomia na Moda, Moda e design de superfície, Moda e Sustentabilidade, Calçados, Análise de artefatos de Moda, Epistemologia do Design de Moda, Moda e Tecnologia, Acessórios de Moda, Moda e Criatividade e Moda e Fetichismo.

Com a criação das categorias, foram descartados artigos que não se enquadravam nas mesmas. Por exemplo, trabalhos de áreas correlatas como design em geral, arquitetura, sociologia, arte entre outros, que não tratavam especificamente de assuntos de moda, moda na definição desta pesquisa. Excluindo esses artigos, permaneceram duzentos e vinte e quatro artigos e, para esses, foram coletados outros dados relevantes ao trabalho presente, como o tipo de pesquisa, o tipo de coleta de dados utilizada, se a pesquisa era de caráter qualitativo ou quantitativo, o objeto de pesquisa e os autores.

É importante destacar que alguns trabalhos não mencionavam a instituição de ensino à qual pertenciam, e foram classificadas como "outras". Como apresentado em seção posterior, muitos trabalhos não apresentavam dados de metodologia de pesquisa científica ou coleta de dados. Para que fosse possível completar os dados, foi necessário definir, através de leitura e interpretação dos artigos com base em Sampieri et. al. (1997) e Lakatos e Marconi (2009), os dados de metodologia e coleta de dados.

Com base nesse levantamento, criou-se um campo na tabela que classifica o nível de informação no artigo sobre a metodologia. Em alguns casos, o estudo não mencionava metodologia; em alguns casos abordava-a de forma superficial, apresentando um ou dois dados no resumo ou na introdução. Outros abordavam a metodologia de forma mais detalhada, fornecendo mais informações sobre a metodologia, um resumo mais completo e, em alguns casos, até apresentavam uma seção específica sobre a metodologia.

A etapa seguinte tratou da correção e do ajuste no formato dos dados. No caso do software escolhido, foi necessário realizar codificação - substituindo dados por códigos numéricos, e em alguns casos por palavras. Estas substituições são feitas conforme a tarefa e a técnica de mineração de dados escolhidas no software.

\subsection{Mineração de Dados}

A mineração de dados ${ }^{6}$ trata de uma das etapas do processo conhecido como Descoberta de Conhecimento em base de dados. Segundo Goldschimidt e Passos (2005), a descoberta do conhecimento em Bases de Dados - também chamada de Knowledge Discovery in Data Bases (KDD) - é um processo composto por três fases: Pré-processamento, Mineração de Dados e Pós Processamento.

A figura 2 apresenta as principais tarefas da mineração de dados (inserida no processo de descoberta de conhecimento em base de dados).

\footnotetext{
${ }^{6}$ A Mineração de dados é abordada mais detalhadamente em: HORN, B. S. Uma análise da pesquisa em design de moda no Brasil a partir de periódicos da área. 2014. Dissertação (Mestrado) Centro Universitário Ritter dos Reis, Curso de Pós-Graduação em Design.
} 


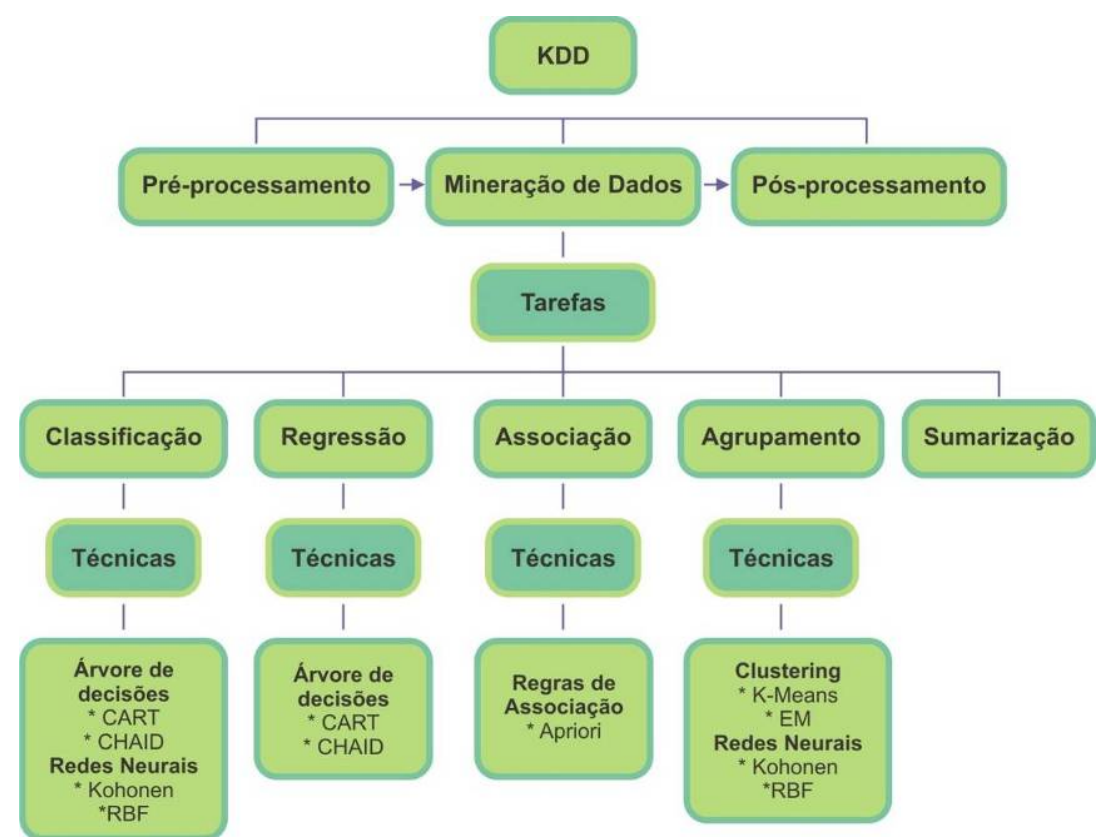

Figura 2 - Processo de KDD e Mineração de Dados.

Fonte: Elaborado pelo autor, com base na pesquisa realizada.

Verificam-se as três etapas citadas anteriormente, em seguida as tarefas de mineração de dados, e algumas técnicas ou algoritmos básicos de mineração de dados. Observa-se que as tarefas e técnicas aqui apresentadas não englobam todas as funções da mineração de dados.

A mineração de dados trabalha com uma série de tarefas, e com uma considerável quantidade de técnicas distintas. No presente trabalho foram utilizadas a clusterização - ou agrupamento - e a associação por regras, pois são as tarefas mais clássicas da mineração de dados, e relevantes para o presente trabalho. Para realização das análises, foi utilizado o software Rapidminer. $^{7}$

\subsection{Pós-processamento}

Nesta etapa optou-se pela simplificação e redesenho de alguns gráficos. Desta forma, ficaram mais claros, apresentando os dados com seus nomes, não somente com dados numéricos. Também foram utilizadas as funções de estatística descritiva do Microsoft Excell - gerando assim dados quantitativos para alguns pontos que eram relevantes.

\section{ANÁLISE DOS RESULTADOS}

Devido ao grande número de resultados gerados, serão apresentados aqui apenas alguns como prova de conceito, e uma síntese de todos ao final na seção seguinte. Mais resultados podem ser verificados na dissertação ${ }^{8}$ de mestrado.

Sobre as Instituições de Ensino, na figura 3 pode-se verificar quais são as que mais geraram publicações. Muitas não tem a instituição identificada, mas no caso das identificadas, UDESC, PUC-SP, UFSC e SENAC-SP aquelas que têm maior número de publicações.

\footnotetext{
${ }^{7}$ Disponível em http://rapid-i.com/

${ }^{8}$ HORN, B. S. Uma análise da pesquisa em design de moda no Brasil a partir de periódicos da área. 2014. Dissertação (Mestrado) Centro Universitário Ritter dos Reis, Curso de Pós-Graduação em Design.
} 


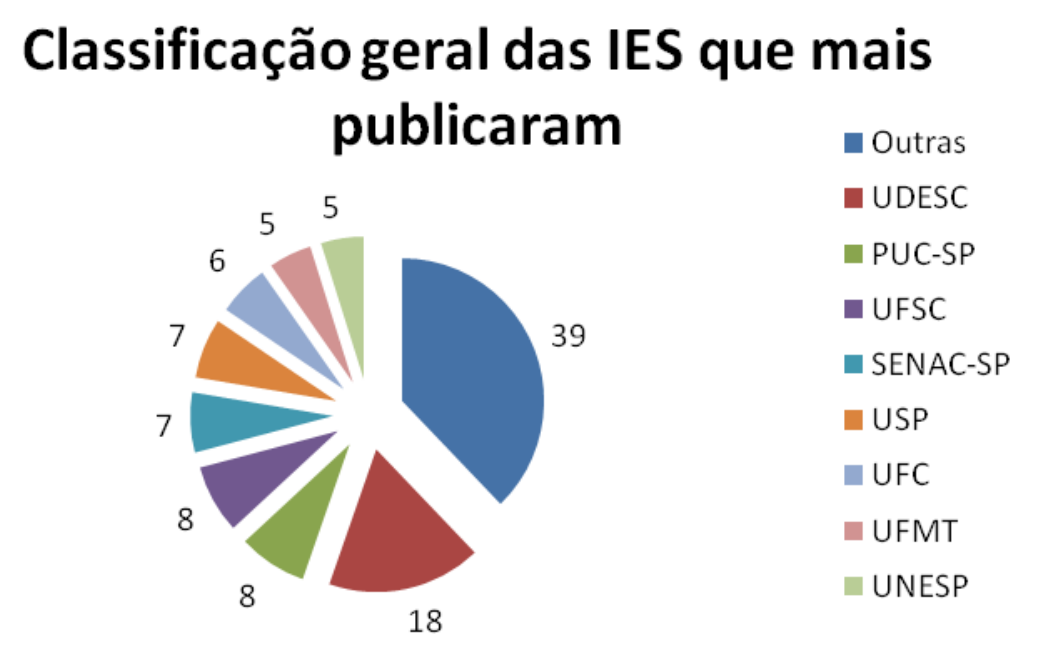

Figura 3 - Estatística Descritiva das instituições de ensino que mais publicaram.

Fonte: Elaborado pelo autor, com base na pesquisa realizada.

Um dos pontos mais relevantes para o problema da pesquisa é a metodologia de pesquisa utilizada nos artigos analisados, por se tratar de um trabalho voltado para epistemologia do design de moda. Como já foi mencionado em seção anterior, criou-se uma classificação para abordagem científica, que resultou em 167 artigos que não mencionam metodologia, 30 que mencionam a metodologia, porém não dão informações completas e 27 artigos que mencionam a metodologia detalhadamente.

No exemplo da figura 4, o periódico que mais "utilizou detalhadamente" metodologias de pesquisa, bem como "abordagem superficial" foi o periódico Modapalavra; na categoria "não abordavam metodologias", os três periódicos obtiveram quantidades similares.

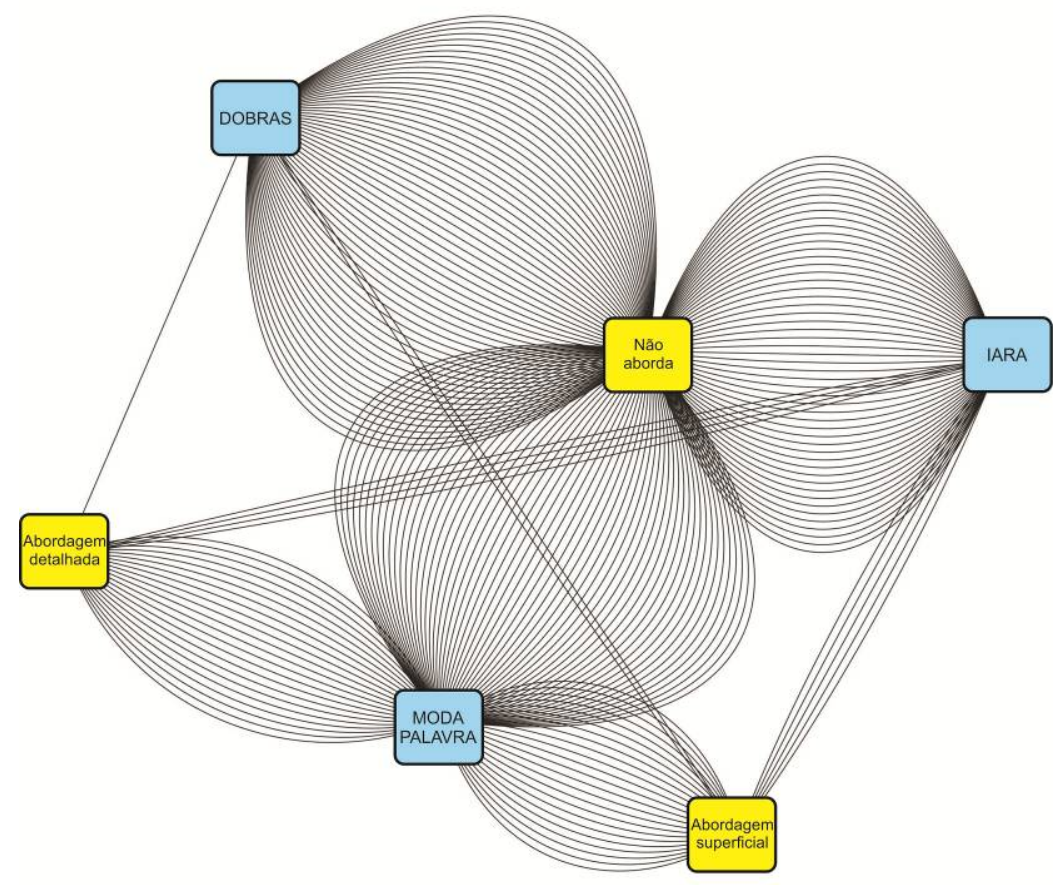

Figura 4 - Abordagem de metodologia científica.

Fonte: Elaborado pelo autor, com base na pesquisa realizada. 
Na figura 5, observa-se algumas regras obtidas a partir dos dados da revista IARA. Pode-se afirmar que 95,5\% dos artigos que são do tipo "pesquisa bibliográfica" e utilizam somente coleta bibliográfica - o que implica artigos que não abordam qualquer outra metodologia de pesquisa com dados primários. Esta regra acontece em $35 \%$ dos artigos cadastrados na base de dados da IARA, somando 60 artigos.

Outra regra presente é que $31 \%$ dos artigos de caráter qualitativo implicam artigos que abordam a categoria Moda e Sociedade - esta regra, por exemplo, ocorre em $30 \%$ dos artigos da revista IARA.

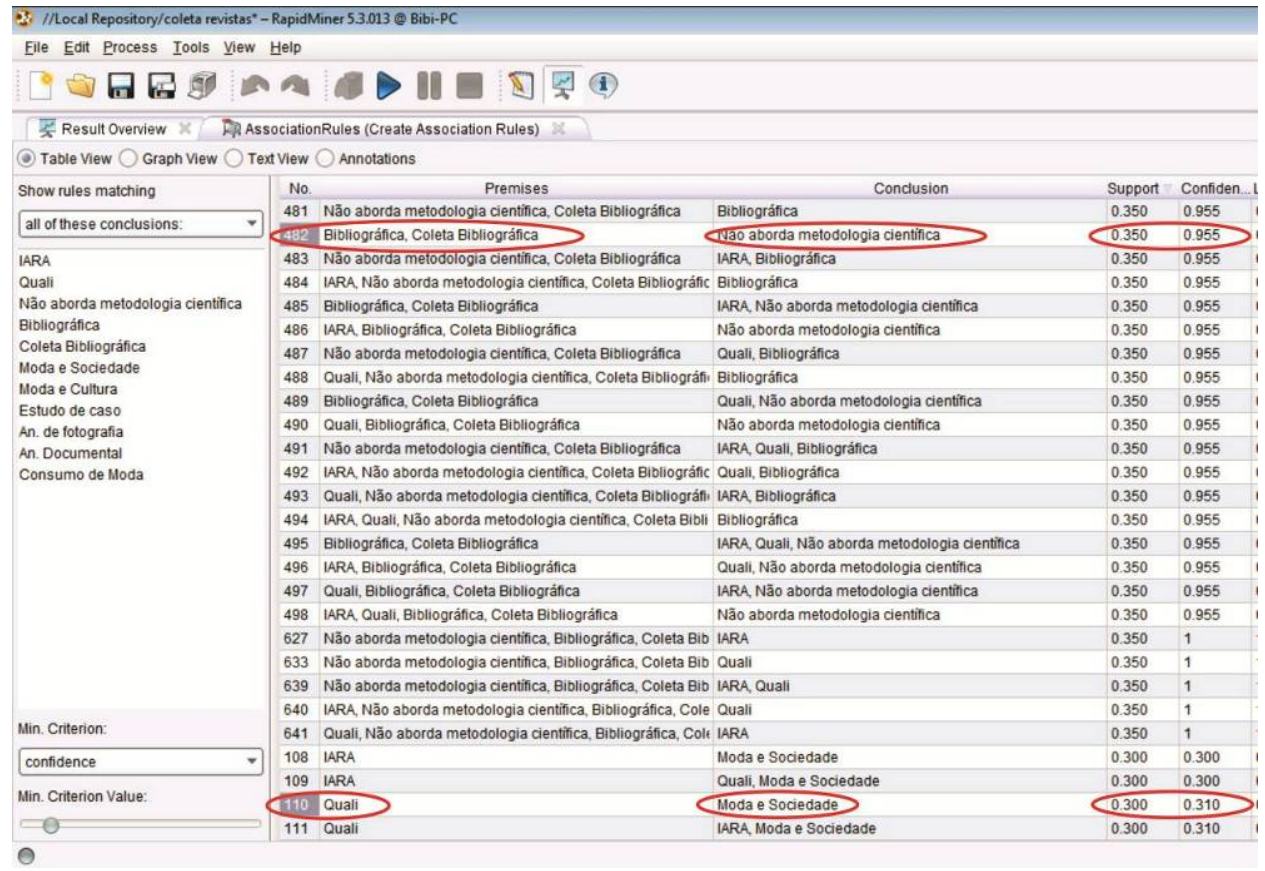

Figura 5 - Regras na revista IARA.

Fonte: Elaborado pelo autor, com base na pesquisa realizada.

Essas análises foram aplicadas para identificar diversas informações, como temáticas mais pesquisadas, métodos de pesquisa e coletas de dados mais utilizados, instituições com maior número de publicações, periódicos que mais aborda a metodologia de pesquisa, caráter das pesquisas.

Além do panorama geral da espistemologia em design de moda, também foi possível construir um perfil de tendência de cada periódico através dos resultados obtidos.

\section{CONCLUSÃO}

Através dos dados verificados e de todos os resultados gerados obteve-se um panorama geral da pesquisa do design de moda em periódicos nacionais, específicos da área. Obteve-se um grande número de categorias temáticas - observa-se, porém, haver grande concentração de trabalhos nos temas "Moda e Sociedade" e "História da Moda", apesar dessas serem categorias amplas, que podem abordar uma diversidade de assuntos dentro destes temas. Observa-se que temas mais técnicos de Moda não são abordados com muita frequência no caso desses períodos e nesses periódicos analisados. 
Sobre as intituições com maior número de publicações, a UDESC lidera as instituições com mais artigos publicados, seguida da PUC-SP e da UFSC. Lembrando que foi considerado, para esse cômputo, referências a publicações de apenas uma determinada instituição, e não de instituições agrupadas a outras intituições. Percebese que duas destas instituições são do mesmo estado, e que pertencem a uma região de indústria têxtil muito forte. Essa informação reforça a idéia de Pires(2002), de que um dos motivos para o sugimento dos primeiros cursos de Moda seria a necessidade de mão de obra qualificada. Com isso, pode-se sugerir que há a possibilidade destas regiões não somente formarem profissionais para o mercado e indústria, mas também formar pesquisadores, vista a proximidade indústria e academia.

A categoria de "não abordagem de metodologia" ficou evidente, havendo um número significativo de artigos que não abordam métodos de pesquisa e coleta de dados. Quanto aos métodos, a maioria das pesquisas é predominantemente "Pesquisa Bibliográfica", tendo uma pequena variação para "Estudo de Caso". A coleta também é pouco variada pelo grande número de publicações, predominando a coleta puramente "Bibliográfica". "Análise de fotografia" também pode ser considerada recorrente.

Com essas informações, já se esperava um grande número de trabalhos de caráter qualitativo. Porém, não se pode deixar de destacar que, de fato, há poucos artigos que tratam dados quantitativos.

As análises dos resultados foram facilitadas a partir da geração de diversos gráficos ${ }^{9}$. Além do panorama geral da espistemologia em design de moda, também foi possível construir um perfil de tendência de cada periódico, através dos resultados obtidos.

\begin{tabular}{|l|l|}
\hline Perfil Revista Dobras \\
\hline Categorias mais pesquisadas & $\begin{array}{l}\text { História da Moda, Moda e Sociedade e Semiótica na } \\
\text { Moda }\end{array}$ \\
\hline IE com mais publicações & PUC-SP e UFRJ \\
\hline $\begin{array}{l}\text { Métodos de pesquisa mais } \\
\text { utilizados }\end{array}$ & $\begin{array}{l}\text { Pesquisa Bibliográficas Pesquisa Histórica e Estudo } \\
\text { de Caso }\end{array}$ \\
\hline $\begin{array}{l}\text { Coleta de dados mais } \\
\text { utilizadas }\end{array}$ & $\begin{array}{l}\text { Coleta Bibliográfica, Análise de Fotografias e Análise } \\
\text { de Conteúdo }\end{array}$ \\
\hline $\begin{array}{l}\text { Observações } \\
\text { Dos três periódicos analisados é a que menos } \\
\text { aborda metodologia de pesquisa. Possui um } \\
\text { número muito pequeno de pesquisas } \\
\text { Qualitativas/Quantitativas, e não possui pesquisas } \\
\text { quantitativas }\end{array}$ \\
\hline
\end{tabular}

Quadro 1 - Perfil revista Dobras

Fonte: Elaborado pelo autor, com base na pesquisa realizada.

No caso da revista Dobras, trata-se da revista mais antiga dentre os três periódicos, sendo o que menos aborda metodologia de pesquisa e apresenta principalmente Pesquisa Bibliográfica, Pesquisa Histórica e Estudo de Caso. As instituições que mais tem publicações neste periódico são PUC-SP e UFRJ. Apresenta

\footnotetext{
${ }^{9}$ Disponíveis em: A Mineração de dados é abordada mais detalhadamente em: HORN, B. S. Uma análise da pesquisa em design de moda no Brasil a partir de periódicos da área. 2014. Dissertação (Mestrado) Centro Universitário Ritter dos Reis, Curso de Pós-Graduação em Design.
} 
mais Coleta Bibliográfica, Análise de Fotografias e Análise de Conteúdo. As categorias temáticas com maior ocorrência neste periódico são História da Moda, Moda e Sociedade e Semiótica na Moda. A maioria dos trabalhos são de caráter puramente qualitativo. Possui um número muito pequeno de pesquisas Qualitativas/Quantitativas, e não possui pesquisas quantitativas.

\begin{tabular}{|c|c|}
\hline \multicolumn{2}{|c|}{ Perfil Revista IARA: Revista de moda, cultura e arte } \\
\hline Categorias mais pesquisadas & Moda e Sociedade, Moda e Cultura e Moda e arte \\
\hline IE com mais publicações & SENAC-SP e UFC \\
\hline $\begin{array}{l}\text { Métodos de pesquisa mais } \\
\text { utilizados }\end{array}$ & Bibliográfica, Estudo de Caso e Pesquisa Histórica \\
\hline $\begin{array}{l}\text { Coleta de dados mais } \\
\text { utilizadas }\end{array}$ & $\begin{array}{l}\text { Coleta Bibliográfica, Análise documental e Análise } \\
\text { de Fotografia }\end{array}$ \\
\hline Observações & $\begin{array}{l}\text { Possui alguns artigos mais isolados que abordam } \\
\text { metodologia. É o periódico com maior número de } \\
\text { artigos de áreas correlatas, visto que aborda os } \\
\text { seguintes temas já em seu título: moda, arte e } \\
\text { cultura. }\end{array}$ \\
\hline
\end{tabular}

Quadro 2 - Perfil revista IARA

Fonte: Elaborado pelo autor, com base na pesquisa realizada.

Já se esperava o aparecimento do SENAC-SP como uma das instituições que mais publica na revista IARA, pois a revista pertence a instituição.

\begin{tabular}{|l|l|}
\hline \multicolumn{2}{|l|}{ Perfil Revista Modapalavra } \\
\hline Categorias mais pesquisadas & História da Moda, Ensino de Moda e Moda e Sociedade \\
\hline IE com mais publicações & UDESC e UFSC \\
\hline $\begin{array}{l}\text { Métodos de pesquisa mais } \\
\text { utilizados }\end{array}$ & $\begin{array}{l}\text { Pesquisa Bibliográfica, Pesquisa Histórica e Dissertação } \\
\text { Projeto }\end{array}$ \\
\hline $\begin{array}{l}\text { Coleta de dados mais } \\
\text { utilizadas }\end{array}$ & $\begin{array}{l}\text { Coleta Bibliográfica, Análise de Fotografia e } \\
\text { Manufatura/Resultados. }\end{array}$ \\
\hline Observações & $\begin{array}{l}\text { Possui mais artigos com abordagem de metodologia de } \\
\text { pesquisa. Apesar da maioria das publicações serem de } \\
\text { caráter qualitativo. o periódico também traz pesquisas } \\
\text { quantitativas e qualitativas/quantitativas. }\end{array}$ \\
\hline
\end{tabular}

Quadro 3 - Perfil revista Moda palavra

Fonte: Elaborado pelo autor, com base na pesquisa realizada.

Se comparado aos outros dois periódicos, Modapalavra é o que mais apresentaa categoria de "aborda metodologia de pesquisa". UDESC e UFSC são as instituições que mais publicaram, devendo ser considerado que o periódico é publicado pela UDESC e as duas instituições se encontram na mesma região.

Sob um perfil acadêmico, os dados sugerem que a Revista Modapalavra tem uma tendência maior a trabalhar com artigos que seguem mais práticas metodológicas. Neste ponto de vista a revista IARA seria intermediária - porém podese perceber que ela respeita os diversos temas a que se propõe abordar: moda, cultura e arte. E por fim, a revista que estaria menos enquadrada em um perfil de práticas 
metodológicas seria a Dobras - no entanto, deve ser destacado que o periódico atende o seu propósito: "uma revista de moda mas não só, acadêmica mas nem tanto."

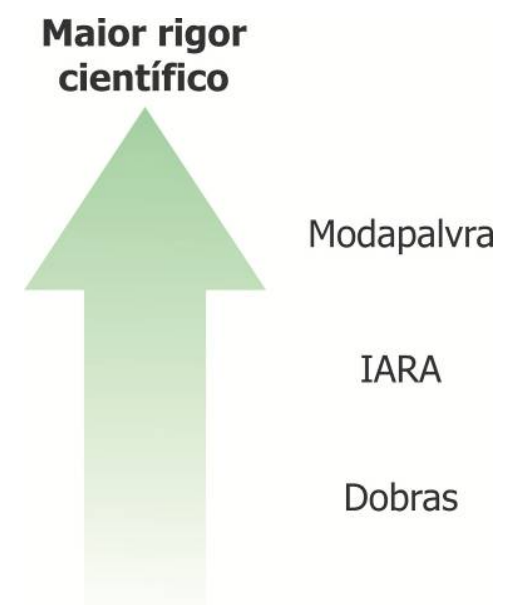

Figura 2 - Perfil acadêmico das revistas

Fonte: Elaborado pelo autor, com base na pesquisa realizada.

Ainda é possível refletir acerca das categorias temáticas pesquisadas. Com base na pesquisa teórica realizada para este trabalho, Pires (2002) afirma que as escolas de moda no Brasil surgiram da necessidade de proficionais capacitados para atender 0 mercado e indústria. Assim, teve origem na prática, com um perfil tecnicista. Porém, o que se percebe hoje é a falta de bibliografia e materiais científicos confiáveis, com trabalhos validados pelos resultados obtidos. Isso pode ser verificado pelas categorias mais pesquisadas, nos periódicos analisados.

Com isso é possível levantar os seguintes questionamentos para futuros trabalhos: porque uma área da prática e técnica resultou em pesquisas opostas a esse perfil tecnicista? A utilização de metodologia de pesquisa científica, coleta e análise de dados, e pesquisas voltadas para questões mais técnicas da moda iriam contribuir para consolidação da área como ciência? Pesquisas com caráter mais técnico podem aproximar o mercado e a indústria da academia?

Em relação à metodologia utilizada, o presente estudo contribui para futuras pesquisas que poderão vir utilizar este tipo de metodologia para trabalhos das mais diversas áreas. Um possível trabalho futuro é emprego de técnicas de mineração de textos sobre os resumos - ou mesmo sobre os textos completos - desses trabalhos, esperando-se obter informações mais ricas. Um trabalho que empregue essa técnica pode apoiar a definição de perfis de periódicos - permitindo, assim, que pesquisadores possam analisar outros periódicos, vindo a formar um banco de perfis de periódicos para seus grupos de pesquisa.

\section{AGRADECIMENTO}

A primeira autora agradece à Capes pelo apoio financeiro recebido para esta pesquisa. 


\section{REFERÊNCIAS}

ANDRADE NETO, Mariano Lopes. A produção científica de Design de Moda no Brasil: um estudo bibliométrico. Disponível na internet por http em: <http://sitios.anhembi.br/damt/arquivos/1.pdf.> Acesso em: 9 jun. 2013.

BONADIO, Maria Claudia. A produção acadêmica sobre moda na pós-graduação Stricto Sensu no Brasil. IARA: revista de Moda, Cultura e Arte. São Paulo, v.3, n.3, 2010.

CALANCA, Daniela. História social da moda. São Paulo: Senac, 2008.

CALDAS, Dário. Observatório de sinais: Teoria e prática da pesquisa de tendências. Rio de Janeiro: Senac, 2006.

CONTI, Giovanni Maria. Moda e cultura de projeto industrial: hibridação entre saberes complexos. In: PIRES, Dorotéia Baduy (Org.). Design de moda olhares diversos. Barueri: Estação das Letras, 2008.

FIORINI, Verônica. Design de moda: abordagens conceituais e metodológicas. In: PIRES, Dorotéia Baduy (Org.). Design de moda olhares diversos. Barueri: Estação das Letras, 2008.

GOLDSCHIMITD, Ronaldo; PASSOS, Emmanuel. Data Mining - um guia prático. Rio de Janeiro: Elsevier, 2005.

HORN, B. S. Uma análise da pesquisa em design de moda no Brasil a partir de periódicos da área. 2014. Dissertação (Mestrado) Centro Universitário Ritter dos Reis, Curso de Pós-Graduação em Design.

LAKATOS, Eva Maria; MARCONI, Marina de Andrade. Metodologias do Trabalho Científico. São Paulo: Atlas, 2009.

LIPOVESTKY, Gilles. O império do efêmero: a Moda e seu destino nas sociedades modernas. São Paulo: Editora Schwarcz LTDA., 2009.

PIRES, Dorotéia Baduy. A história dos cursos de design de moda no Brasil. Revista Nexos: Estudos em Comunicação e Educação. São Paulo, n.9, ano VI, 2002.

SABINO, Marco. Dicionário da Moda. Rio de Janeiro: Campos, 2007.

SAMPIERI, C. Roberto Hernández et. al. Metodología dela investigación. Colombia: Panamericana Formas e Impresos S.A., 1997.

SVENDSEN, Lars. Moda: uma filosofia. Rio de Janeiro: Zahar, 2010

TREPTOW, Doris. Inventando Moda: Planejamento de Coleção. Brusque: Ed. do Autor, 2003 